\title{
Interfant-06 Protocol
}

National Cancer Institute

\section{Source}

National Cancer Institute. Interfant-06 Protocol. NCI Thesaurus. Code C156939.

A clinical study protocol initiated in 2006 designed to improve the treatment for infant acute lymphoblastic leukemia. 